\section{The effect of removal of the warning stimulus from a schedule of free operant avoidance*}

\author{
ARNOLD HYMAN† \\ Department of Surgery \\ Jewish Hospital and Medical Center of Brooklyn, Brooklyn, N.Y. 11238
}

Three rhesus monkeys were run to a steady-state criterion on a schedule of free operant discriminated avoidance, after which the warning stimulus was removed from the schedule and the animals were stabilized on the nondiscriminated schedule. The effects of the removal of the warning stimulus included increased response rate, a shift to shorter IRTs, and increased shock rate.

Free operant (Sidman) avoidance may be presented with and without a preshock warning stimulus, the former being termed discriminated and the latter, nondiscriminated. The differences in behavior generated by the two paradigms have been studied by Sidman (1955), Sidman \& Boren (1957), and Keehn (1959) in the rat, by Behrend \& Bitterman (1963) in the fish, and by Sidman, Mason, Brady, \& Thach (1962) in the monkey. There is general agreement that the insertion of the warning stimulus into the avoidance schedule brought about a shift to longer interresponse times (IRTs), thereby lowering response rate. The Ss tended to wait for the warning stimulus before responding. Behrend \& Bitterman (1963) also reported lower shock rates under the nondiscriminated paradigm.

However, detailed data for the monkey concerning changes in IRT distributions, conditional probability of response, response rate, and shock rate as a function of the presence or absence of the warning stimulus in free operant avoidance, as well as the transition behavior generated by the removal of the warning stimulus, have not been reported. The study of Sidman et al (1962) was concerned mainly with the relations between avoidance behavior and pituitary-adrenal cortical activity and, therefore, did not report such behavioral data in very much detail. The present paper is a report of behavioral changes as a function of the removal of the warning stimulus from a schedule of free operant discriminated avoidance in the rhesus monkey.

\section{SUBJECTS}

Three rhesus monkeys, one male

*Supported by National Institute of Child Health and Human Development (Grant 5 P01 HD03113 HDP).

+Now at Adelphi University. Garden City, N.Y. and two female, approximately $1 \frac{1 / 2-2}{2}$ years of age, were employed. Two were born and raised in the laboratory, one was feral. They were housed in individual cages and maintained on commercial chow and water.

\section{APPARATUS}

During the sessions, the animals were restrained in a specially constructed chair which was placed in a sound-attenuating cubicle. A response lever (Lehigh Valley Electronics No. 194-12) was located directly in front of the animal. Shock was delivered to the tail from a constant-current source (Foringer Model 1154) through electrodes made from modified clip leads (Muller No. $27 \mathrm{C}$ ). Standard electromechanical and reed relays were used for the programming and control of the experiment. The warning stimulus was white noise which raised the sound level in the region of the animal's head from the ambient noise level of 50 to $74 \mathrm{~dB}$ (A scale).

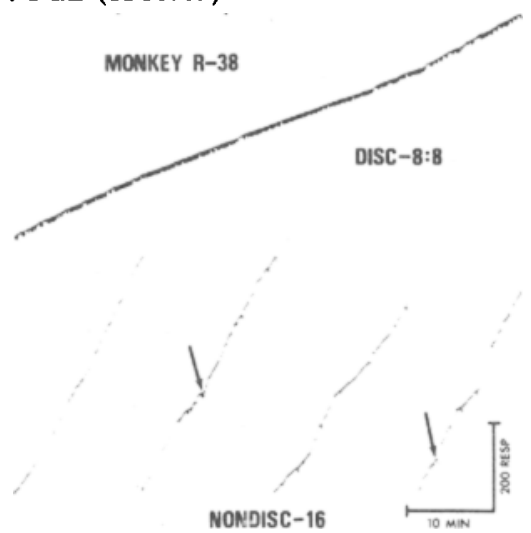

Fig. 1. Typical cumulative records for steady state behavior. In the upper record, the oblique marks indicate warning stimuli; in the lower record the marks indicate those points at which a warning stimulus would have come on if the procedure had been discriminated avoidance. The arrows indicate shocks.
PROCEDURE

Two avoidance paradigms were employed: free operant discriminated avoidance and free operant nondiscriminated avoidance. In the nondiscriminated case, brief inescapable shocks were delivered periodically at an interval referred to as the shock-shock interval. A leverpress interrupted the sequence of shocks by delaying the subsequent one for a fixed period of time, referred to as the response-shock interval. In the present study, the response-shock and shock-shock intervals were both set at $16 \mathrm{sec}$. The presence of a preshock warning stimulus created the discriminated paradigm. The response-shock and shock-shock intervals were divided into two parts, the safe stimulus (or RS, interval) and the warning stimulus (or $S_{1} S_{2}$ interval). In the present case, each of the intervals was set at 8 sec. A response during the safe stimulus postponed the warning stimulus and the shock; a response during the warning stimulus terminated it and postponed the shock. The response, rather than interrupting a series of shocks only, interrupted a sequence of warning stimuli and shocks.

In order to facilitate learning of the avoidance response, the monkeys were initially taught to press the bar for a food reinforcer (Ciba 190-mg nutrient pellets, Catalog No. 5902). After they had worked for several sessions for food, the discriminated avoidance schedule, which will be referred to as DISC-8:8, was introduced. Both the positive and the avoidance schedule were in effect for two sessions.

Following the acquisition of the avoidance response, the monkeys continued to work under DISC-8:8 until each had generated 8 sessions of steady-state behavior. The warning stimulus was then removed from the schedule, putting into effect the nondiscriminated schedule (NONDISC-16). The animals were run on it for 18 sessions. The last 8 sessions provided the steady-state behavior sample which is analyzed in this paper. A steady state was determined to be in effect when trends ceased to appear in the data.

RESULTS

Steady-State Data

Response rate was higher for all Ss when the warning stimulus was not included in the schedule (Table 1, Fig. 1). Concomitant shifts in the relative IRT distributions were observed (Fig. 2). Under DISC-8:8, the modal IRT interval was, in all cases, $8-10$ sec, while under NONDISC-16, it was $0-2$ sec. Without the waming stimulus, the animals rarely paused $8 \mathrm{sec}$ after responding, whereas they quite regularly did so when the 
Table 1

Responses Per Minute

\begin{tabular}{lrrrr} 
& \multicolumn{2}{c}{ DISC-8:8 } & \multicolumn{2}{c}{ NONDISC-16 } \\
\cline { 2 - 5 } Monkey & \multicolumn{1}{c}{ M } & SD & \multicolumn{1}{c}{ S } \\
\hline R-65 & 10.10 & 1.10 & 23.83 & 4.81 \\
R-38 & 8.25 & 0.98 & 32.20 & 5.73 \\
R-9 & 8.75 & 1.13 & 51.21 & 12.07 \\
\hline
\end{tabular}

stimulus was available.

The conditional probability curves (IRTs/op) were markedly different under the two conditions (Fig. 2). During DISC-8:8, probability was very low in the absence of the signal and very high in its presence. The curves for NONDISC-16 show no such unanimity, since their shapes are different for each of the three Ss. However, they are all characterized by an absence of extreme differences in probability, as opposed to the DISC- $8: 8$ curves.

Shock rate was higher for all Ss under the nondiscriminated schedule than under the discriminated schedule, though not markedly so (Table 2 and Fig. 1). The increase in IRTs greater than $16 \mathrm{sec}$ that accompanied the increase in shock rate was, however, too small a percentage of the total to be seen in the distributions in Fig. 2 .

Transition Data

The removal of the warning stimulus was accompanied by a sharp increase in shock rate, which then declined gradually throughout the transition period. The decline in shock rate was accompanied by a gradual increase in response rate, which reflected a gradual shift to shorter IRTs. The shift is not shown, due to space limitations. The transition period was considered over when both shock rate and response rate reached stable levels, after Session 8 of NONDISC-16 (Fig. 3). In actual practice, however, as previously stated, steady-state data were not taken until Session 11 of NONDISC-16, in order to be absolutely certain that the steady-state data were not contaminated with transition data.

\section{DISCUSSION}

The relative IRT distributions demonstrate that the warning stimulus in the present study had an effect similar to that observed in the studies of Behrend \& Bitterman (1963) with the goldfish, of Sidman (1955) with the cat, of Sidman (1955), Sidman \& Boren (1957), and Keehn (1959) with the rat, and of Sidman et al (1962) with the rhesus monkey. The animals utilized the stimulus as an occasion for responding, as demonstrated by the IRT data.

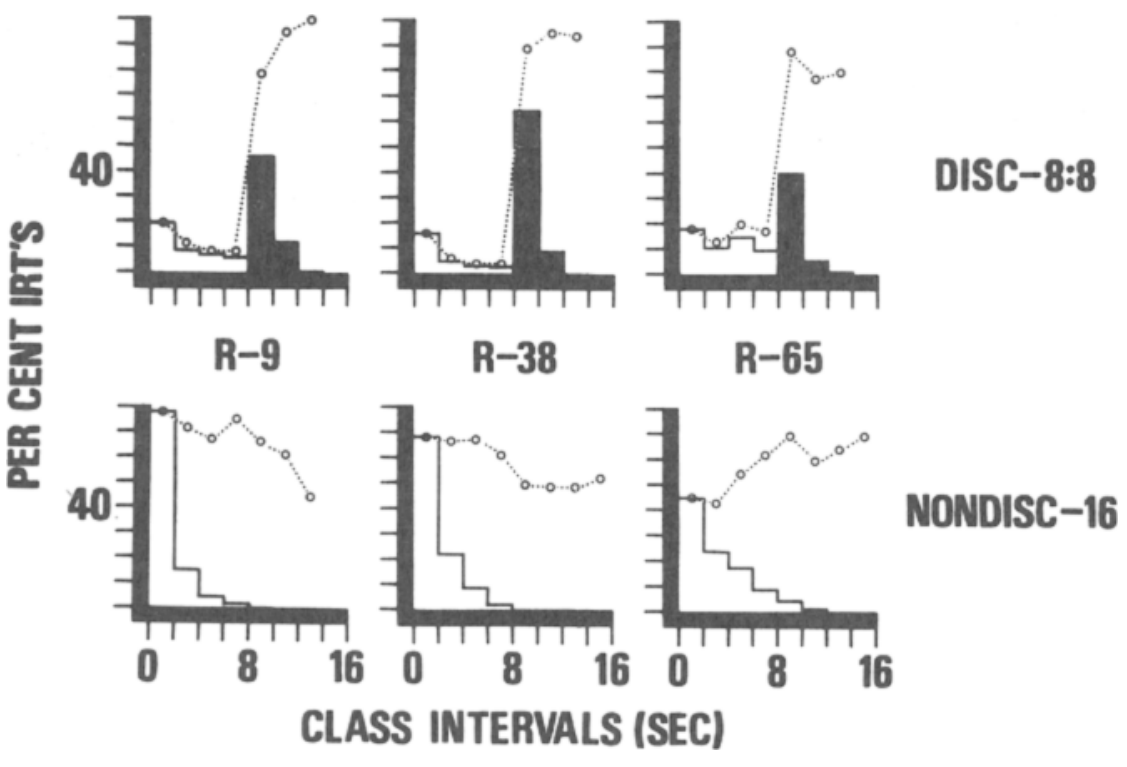

Fig. 2. Relative IRT distributions and conditional probability curves. The filled in portions of the bars indicate responses emitted in the presence of the warning stimulus. The dotted line represents IRTs per opportunity to respond. Each graph represents, for each animal, the total number of responses emitted during the eight sessions of steady state behavior at each schedule.
According to an interpretation of free operant avoidance by Anger (1963), the preponderance of short IRTs in the nondiscriminated schedule indicated that nonavoidance behavior became aversive very shortly after an avoidance response, although shock was not due for a relatively long time. The presence of a warning stimulus in the schedule created a readily discriminable safe period (or safe stimulus), in the present case lasting for 8 sec after a response, during which the animal was never shocked. This situation favored a relatively low probability of responding during the safe stimulus. Without the warning stimulus, the entire response-shock interval was homogeneous with regard to exteroceptive stimulation so that there was no readily discriminable safe period. This situation favored the formation of a flat temporal generalization gradient, expressed as a preponderance of short IRTs.

In contrast to the present findings, Sidman (1955) reported that his Ss continued to generate long IRTs after the removal of the warning stimulus. He described the Ss as having formed a "temporal discrimination [p. 446]." Though his Ss had been exposed to nondiscriminated avoidance before, as well as after, the discriminated paradigm, this difference in procedure hardly seems sufficient to explain this discrepancy in results, the explanation of which remains obscure.

As implied above, Sidman, in his earlier usage $(1954,1955)$, contended that a preponderance of short IRTs was an indication that an animal had not formed a temporal discrimination. Subsequently, Sidman, himself (1966), Anger (1963), and Hineline \& Herrnstein (1970) rejected the earlier hypothesis, pointing out that IRT distributions may obscure the fact that the conditional probability of response is usually very high for long IRTs, even though such IRTs may be relatively few in number (as in the present experiment). This high conditional probability is taken as evidence that the animal has formed a temporal discrimination. It has become an accepted practice, therefore (Anger, 1963; Sidman, 1966; Hineline \& Herrnstein, 1970), to publish curves of conditional probability (IRTs/op) as well as IRT distributions (see Fig. 2). However, Hineline and Herrnstein's contention that a flat curve of conditional probability indicates a lack of timing behavior appears to be in error. The very fact that an animal is able to perform free operant avoidance indicates that he has formed a temporal discrimination, since the majority, and in some cases, the overwhelming majority, of IRTs are always less than the response-shock or shock-shock interval. 
Table 2

Shocks Per Hour

\begin{tabular}{lcc}
\hline & $\begin{array}{c}\text { DISC- } \\
\text { Monkey }\end{array}$ & $\begin{array}{c}\text { NONDISC- } \\
\text { R-65 }\end{array}$ \\
\hline R-38 & 0.38 & 16 \\
R-9 & 0.12 & 1.75 \\
\hline
\end{tabular}

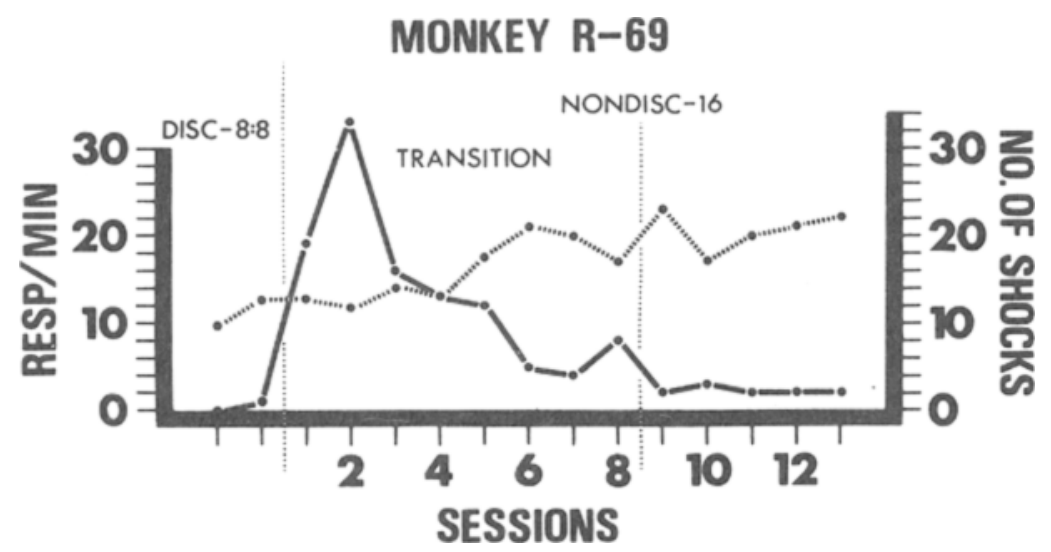

Fig. 3. Changes in response rate and shock reception during the transition from DISC-8:8 to NONDISC-16. The last two DISC-8:8 sessions are included for comparison, as are five sessions of steady state behavior under NONDISC-16. The solid curve represents shocks, the dotted one response rate.

In the present study, the generalization that emerges from the behavior on both schedules is that the large majority of responses occurred within 1 -4 sec of a clearly discriminable event-the animal's response when no warning stimulus was available and the warning stimulus oriset during the discriminated schedule. The animals made relatively few attempts to wait longer, since long IRTs had become associated with shock. The negative correlation between response rate and shock rate during the transition period (Fig. 3) indicates that the reception of shocks was associated with the shift from longer to shorter IRTs. As previously stated, the IRT shift during transition is not shown but may be inferred from the increases in response rate. The IRT shift was reinforced by the reduction in shock rate.

Two properties of the conditional probability curves (Fig. 2) indicate that the discriminated schedule exerted a greater degree of behavioral control than did the nondiscriminated schedule, a phenomenon that has been referred to as stimulus control of avoidance behavior (Ulrich, Holz, \& Azrin, 1962). The curves for DISC-8:8 not only show the extreme differences in probability previously described. but are also quite uniform across Ss. Those for NONDISC-16 exhibit neither of these characteristics. The occurrence of responses was more predictable under DISC-8:8 than under NONDISC-16. REFERENCES
ANGER, D. The role of temporal
djscriminations in the reinforcement of
Sidman avoidance behavior. Joumal of
the Experimental Analysis of Behavior.
$1963,6,477-506$.

BEHREND, E. R., \& BITTERMAN, M. E. Sidman avoidance in the fish. Journal of the Experimental Analysis of Behavior. $1963,6.47-52$.

MINELINE. P. N., \& HERRNSTEIN, R, d. Timing in free-operant and discrete-tria avoidance. Journal of the Experimental Analysis of Behavior, 1970, 13,113-126.

KEEHN, J. D. The effect of a waming signal on unrestricted avoidance behavior. British Journal of Psychology, 1959, 50. 125-135.

SIDMAN. $M$. The temporal distribution of avoidance responses. Journal of Comparative \& Physiological Psychology. $1954,47,399-402$.

SIDMAN. M. Some properties of the waming stimulus in avoidance behavior. Journal of Comparative \& Physiological Psychology, 1955, 48, 444-450.

SIDMAN, M. Avoidance behavior. In $W . K$. Honig (Ed.), Operant behavior: Areas of researef and application. New York: Appleton-Century-Crofts, 1966 .

SIDMAN M. BOREN, J. J. A comparison of two types of waming stimulus in an avoidance situation Joumal of Comparative \& Physiological Psychology, 1957, 50, 282.287.

SIDMAN, M. MASON, J. W., BRADY, J. V., \& THACH, J., JR. Quantitative relations between avoidance behavior and pituitary-adrenal cortical activity. Joumal of the Experimental Analysis of Behavior. $1962,5,353-362$.

ULRICH, R. E., HOLZ, W. C. \& AZRIN, N. H. Stimulus control of avoidance behavior. Joumal of the Experimental Analysis of Behavior, 1964, 7, 129133 